\title{
MENINGKATKAN KEMAMPUAN BERBAHASA SUNDA ANAK USIA DINI MELALUI KEGIATAN REBO NYUNDA DI PENDIDIKAN ANAK USIA DINI
}

\author{
Anni Risnawati ${ }^{1}$, Lenny Nuraeni ${ }^{2}$ \\ ${ }^{1}$ Institut Keguruan dan Ilmu Pendidikan (IKIP) Siliwangi, Cimahi. \\ ${ }^{1}$ Institut Keguruan dan Ilmu Pendidikan (IKIP) Siliwangi, Cimahi \\ 1 annirisnawati16@gmail.com, ${ }^{2}$ lennynuraeni86@ikipsiliwangi.ac.id
}

\begin{abstract}
Communication skills of each person can be formed, from early childhood, without the ability to speak someone can not communicate or convey what he feels to others. Sundanese as the language of instruction in West Java began to be introduced to early childhood as a stimulation so that early childhood know their mother tongue which is the everyday language of instruction in their home environment, but Sundanese language has been eroded by modernization which considers Sundanese not as good as language Indonesian or English, therefore many children in the family environment do not use Sundanese, as a daily language of instruction. In line with the statement of the District Government of Bandung, it has set local content in the concept of Rebo Nyunda, by instilling values that have local kearipan and can characterize children, so that they are expected to be independent and competitive as a support for the realization of the community order, especially in the district Bandung.
\end{abstract}

Keywords: Language ability, Sundanese, Rebo Nyunda.

\begin{abstract}
ABSTRAK
Kemampuan komunikasi setiap orang dapat terbentuk, dari masa anak usia dini, tanpa kemampuan berbahasa seseorang tidak dapat berkomunikasi atau menyampaikan apa yang dirasakannya kepada orang lain. Bahasa Sunda sebagai bahasa pengantar di Jawa Barat mulai diperkenalkan kepada anak usia dini sebagai sebuah stimulasi agar anak usia dini mengenal bahasa ibunya yang menjadi bahasa pengantar sehari-hari dilingkungan rumahnya, tetapi bahasa sunda sudah terkikis keberadaanya oleh modernisasi yang menganggap bahwa bahasa sunda tidak sebagus bahasa indonesia atau bahasa inggris oleh karena itu banyak anak yang di lingkungan keluarganya tidak menggunakan bahasa Sunda, sebagai bahasa pengantar sehari- hari. Sejalan dengan pernyataan Pemerintah Daerah Kabupaten Bandung telah menetapkan muatan lokal dalam konsep Rebo Nyunda, dengan menanamkan nilai-nilai yang memiliki kearipan lokal dan dapat menunbuhkan karakter pada diri anak, sehingga diharapkan menjadi manusia yang mandiri dan berdaya saing sebagai penopang perwujudan tatanan masyarakat khususnya di kabupaten Bandung.

Kata kunci : Kemampuan berbahasa, Bahasa Sunda, Rebo Nyunda.
\end{abstract}

\section{PENDAHULUAN}

Bahasa merupakan tanda atau simbol dari suatu benda serta menunjukkan pada maksud-maksud tertentu, seperti kata, kalimat sehingga memunculkan arti yang baru, sehubungan dengan arti simbolik, bahasa dipakai juga sebagai alat komunikasi lisan antar manusia dalam bentuk lisan, tulisan atau isyarat. Chomsky (1968) berpendapat bhawa kecepatan anak dalam berbicara atau kata pertama bagi seorang anak merupakan salah satu keajaiban alam 


\section{JURNAL GERIA}

ISSN : 2614-6347 (Print) 2714-4107 (Online)

Vol.2 | No.3 | September 2019

dan menjadi bukti kuat dari dasar biologis untuk memperoleh kemampuan berbahasa.

Menurut Garder (dalam Amstrong, 1996) menyatakan bahwa kecerdasan linguistik pada awal masa kanak-kanak akan terus bertahan hingga usia lanjut. Pengembangan bahasa untuk Anak Usia Dini difokuskan pada keempat aspek bahasa yaitu menyimak, berbicara, membaca dan menulis. Dengan menggunakan bahasa untuk berkomunikasi anak dapat menambah kosa kata sekaligus dapat mengekspresikan dirinya, anak juga dapat belajar bagaimana berkomunikasi dan berpartisipasi dalam suatu percakapan dan dapat digunakan sebagi alat untuk memecahkan masalah (Winda dan Azizah Muis , 2008 : 4-16)

Usaha yang dilakukan guru untuk meningkatkan kemampuan Bahasa anak adalah dengan berbagai cara, karena anak - anak seringkali tidak atau bahkan kurang mempunyai kemampuan berbahasa, anak seringkali tidak percaya diri ketika oleh gurunya diminta untuk bercerita misalnya (Fauziddin, 2017)

Pendidikan bertujuan agar budaya yang merupakan nilai bangsa dapat diwariskan dan dimiliki oleh generasi muda agar tidak ketinggalan zaman senantiasa relevan dan signifikan dengan tuntutan hidup , diantara sekian banyak budaya yang diwariskan adalah Bahasa karena Bahasa adalah alat yang sangat penting untuk berkomunikasi .

Setiap negara memiliki Bahasa nasional sendiri sendiri biasanya terdiri dari berbagai Bahasa daerah yang ada , sehingga memungkinkan anak untuk mengetahui lebih dari dua Bahasa atau lebih (Khoiruddin, 2017)

Hal inilah yang kemudian memberikan keinginan kepada peneliti agar menggali lebih jauh tentang ingin lebih meningkatkan kemampuan berbahasa sunda khususnya pada anak usia Dini.

Pengembangan bahasa sunda Pada Pendidikan Anak Usia Dini bertujuan untuk, mengembangkan kosa kata dalam bahasa sunda, membekali anak menggunakan bahasa sunda sehari-hari dan memperluas wawasan budaya sunda

Sejalan dengan muatan lokal Kabupaten Bandung melaui PP Bupati Bandung No 7 Tahun 2013 melalui konsep Rebo Nyunda yang menanamkan kearifan lokal kabupaten Bandung, Rebo nyunda sebagai sebuah kegiatan atau metode yang diharapkan agar anak usia dini dapat menggunakan bahasa sunda sejak dini secara baik dan benar.

Berdasarkan observasi yang sudah dilakukan bahwa kemampuan berbahasa sunda anak usia dini sangat rendah hal inilah yang kemudian memotivasi peneliti untuk lebih menggali kemampuan berbahasa sunda sejak dini ha lini berkaitan dengan keluarga orang sunda sekalipun dalam berbahasa sehari-haripun tidak menggunakan bahasa sunda sebagai bahasa seharihari, karena pernikahan dengan lain suku atau karena merasa malu menggunakan bahasa sunda dibandingkan bahasa indonesia dan bahasa inggris.

Tujuan penelitian ini adalah meningkatkan pengunaan bahasa sunda dengan baik dan tepat melalui kegiatan Rebo Nyunda untuk anak usia dini, Maka dari itu rumusan masalah penelitian ini adalah apakah dengan kegiatan rebo nyunda kemampuan berbahasa sunda anak usia dini dapat ditingkatkan?. Berdasarkan permasalahan tersebut maka peneliti mengajukan penerapan kegiatan mutan lokal Rebo Nyunda untuk meningkatkan kemampuan berbahasa sunda anak usia 


\section{JURNAL GERIA}

ISSN : 2614-6347 (Print) 2714-4107 (Online)

Vol.2 | No.3 | September 2019

dini sebagai alternatif penyelasaian masalah tersebut.

Pada usia 4 tahun Anak Usia Dini mempunyai pembendaharaan kosa kata sebanyak 4000- 6000 kata dan mampu berbicara sebanyak 5- 6 kata , pada usia 5 tahun anak Usia Dini dapat bertambah kosa katanya menjadi 5000- 8000 kata dengan kalimat yang semakin komplek menurut (Carool, Seefelt \& Barbara A, 2008)

Kemampuan berbahasa merupakan salah satu bidang pengembangan kemampuan dasar yang telah dipersiapkan oleh guru untuk meningkatkan kemampuan dan kreatifitas anak yang sesuai dengan tahap perkembangannya, Pengembangan kemampuan berbahasa hendaknya menggunakan pendekatan yang berpedoman pada suatu program kegiatan yang telah disusun pada prinsip-prinsip perkembangan anak, sesuai kebutuhan anak, bermain sambil belajar, menggunakan pendekatan tematik, melalui lingkungan yang kondusif, kreatif, inovatif dan mengembangkan kecakapan hidup.

Bahasa Sunda bagi anak usia dini di Kabupaten Bandung, dijalankan sejalan dengan pernyataan PEMDA Kabupaten Bandung melalui Peraturan Bupati No 7 Tahun 2013 tentang muatan lokal Kabupaten Bandung yaitu kosep Rebo Nyunda. Adapun nilai- nilai karakter yang dikembangkan di satuan Pandidikan Anak Usia Dini :

1. Bahasa Sunda yang diajarkan adalah bahasa sunda yang halus hal ini dapat terlihat dari logat orang sunda yang cenderung lembut serta hormat pada orang tua melalui undak usuk basa atau pembagian tutur kata pada orang yang lebih tua, teman sebaya dan orang yang usianya lebih muda.
2. Melalui nasehat, siloka, tetekon atau paribasa sunda yang diwariskan secara lisan secara turun temurun.

3. Manusia sunda harus senantiasa sopan, sederhana, berani, jujur, teguh pendirian yaitu dengan filsafat cageur, bener, pinter dan singer

4. Harus senantiasa siger tengah artinya tidak berlebihan tidak kekurangan dan tidak berlebihan dalam memenuhi kebutuhan sehari- hari

5. Agama urang sunda adalah Islam dan urang sunda identik dengan islam

6. Nilai sosial urang sunda, menghadapi konflik harus dengan tenang tidak ada permusuhan seperi dalam paribasa berikut tiis ceuli herang mata yang berarti aman dan tentram

7. Melalui paribasa dan babasan yang memberikan tuntunan mengajak berperilaku baik, jangan lupa pada asal-usul kita, orang yang tidak tahu berbalas budi dan sebagainya .

Orang jawa barat memiliki filosofi hidup silih asah, silih asih, dan silih asuh dalam kegiatan pembelajaran dapat disejajarkan dengan ranah kognitif, afektif, psikomotor yang berarti bahwa silih asah ada pada peningkatan kualitas intelegensia mengasah kemampuan otak melalui ilmu dan pemahaman, dengan kemampuan saling asah seorang ilmuan sunda dapat menjadi ilmuan yang beretika dan tidak angkuh. Kemampuan silih asih saling mengasihi satu sama lain yang melahirkan prinsip musyawarah, adil, dan bijaksana sehingga membangun masyarakat kabupaten Bandung yang lebih baik

Pada konsep silih asuh saling bertegur sapa tanpa kebencian, saling 
membimbing, saling menjaga, hal ini pun sejalan dengan konsep cageur, bener, pinter, singer dan wanter yang harus melekat kuat sebagai perwujudan dari pengembangan kemampuan berbahasa sunda yang akan mampu menjadikan anak usia dini di kabupaten Bandung memiliki pemahaman yang sarat makna sesuai dengan muatan lokal kabupaten Bandung yaitu Rebo nyunda. Dengan mensehati anak didik dengan mengungkapkan semboyan hidup atau analogi atau sering disebut juga siloka, hal ini dimaksudkan agar anak didik Mampu menghayati isyarat dalam kehidupan adapun karakter yang diharapkan dari anak didik ketika belajar bahasa sunda melalui siloka atau paribasa yang disebutkan diatas adalah sebagai berikut :

1. Kudu hade gogog hade tagog, harus memiliki penampilan yang percaya diri, optimis dan kharismatik

2. Nyaur kudu diukur nyaba kudu diungang, harus senantiasa menjaga ucapan dan perbuatan agar tidak menyakiti orang lain

3. Batok bulu eusi madu, harus memiliki otak yang cemerlang

4. Ulah bengkung bekas nyalahan, jangan salah dalam bertindak karena akan kembali pada diri sendiri

5. Ulah elmu ajug, tidak menasehati orang lain tetapi diri sendiri tidak baik

6. Sacangreud pageuh sagolek pageuh, harus memiliki prinsip

7. Ulah gindi pikir belang bayah, tidak berbuat jahat dan bersifat dengki

8. Kudu leuleus jeujeur liat tali atau Jangan mudah menyerah

Agar anak didik memiliki etos kerja yang baik melalui filosopi:
1. Mun teu ngoprek moal nyapek artinya kalau tidak berusaha tidak akan dapat memenuhi kebutuhan sehari-hari.

2. Tungkul ka jukut tanggah ka sahandapen, harus fokus.

3. Ulah kumeok memeh dipacok, jangan pernah menyerah.

4. Ulah kurung batok, harus pandai bergaul

5. Ulah cacag nangkaeun, harus seutuhnya tidak setengah setengah

6. Ulah ngrawu kusiku, jangan serakah

7. Ulah hejo tihang, jangan berpindah pidah tempat kerja.

Itulah beberapa contoh penggunaan bahasa sunda yang dapat dianalogikan dan dapat diterapkan pada anak usia Dini tentang beberapa karakter yang harus dimiliki setiap anak didik dan tentu saja banyak siloka atau simbol bahkan analogi lainnya yang kemudian nanti akan dibahas lebih lanjut ( Tim pengembang Sejarah local Kabupaten Bandung Pendidikan Anak Usia Dini, 2013 ).

\section{METODE PENELITIAN}

Metode yang digunakan adalah metode deskriftif yaitu mendeskriptifkan kejadian yang sebenarnya dari suatu penelitian terhadap suatu kegitan yang dilakukan mengenai suatu peristiwa atau gejala dalam penelitian.

Penelitian ini diarahkan untuk mengekplorasi bagaimana aspek - aspek perkembangan untuk selanjutnya menhasilkan apa -apa yang kita inginkan dari kegitan pembelajaran sehingga dibutuhkan suatu analisis untuk mendapatkan informasi juga dapat mendeskripsikan apa saja pengaruhnya bagi Anak Usia Dini, oleh karena itu metode yang digunakan adalah metode deskriptif (Ramdhan, 2016)

tentang bagaimana menigkatkan kemampuan berbahasa sunda pada anak 


\section{JURNAL GERIA}

ISSN : 2614-6347 (Print) 2714-4107 (Online)

Vol.2 | No.3 | September 2019

usia dini melalui kegiatan mutan lokal kabupaten Bandung yaitu kegiatan Rebo Nyunda, dalam proses selanjutnya pengajaran bahasa sunda ini disampaikan melalui kegiatan bermain atau kaulinan barudak dengan metode bermain menggunakan gerakan dan media lain yang mendukung atau melalui kegiatan, ngaregepken atau mendengarkan, nyarita (berbicara), pra maca (sebelum membaca), pra menulis (sebelum menulis ) .(Setiawan, 2012)

Menurut Arikunto (2002), penelitian deskriftif merupakan penelitian yang bertujuan untuk mengumpulkan informasi mengenai status suatu gejala yang ada, yaitu keadaan gajala menurut apaadanya pada saat penelitian dilakukan. Membuat penjelasan secara sistematis, faktual, dan akurat mengenai fakta dan sifat populasi suatu daerah tertentu. Penelitian deskriftif tidak memberikan perlakuan dan manipulasi data tetapi menggambarkan keadaan sebenarnya (Sukmadinata, 2007).

Tahapan pada penelitian ini meliputi tahapan persiapan untuk menentukan kisi-kisi instrumen penelitian yang dilanjuti dengan tahapan pelaksanaan dengan cara mengamati kegiatan pembelajaran. Tahapan pengolahan data dilakukan dengan cara menganalisa kemampuan berbahasa sunda anak usia dini dengan mencoba mengembangkan kemampuan berbahasa sunda melalui kegiatan rebo nyunda. Kegiatan ini melibatkan guru sebanyak 3 orang guru dan anak-anak kelompok B sebanyak 18 orang.

\section{HASIL DAN PEMBAHASAN HASIL}

Penelitian dimulai dari minggu pertama dibulan Januari 2019 dengan 5 kali pertemuan dalam satu bulan jadi penelitian dilakukan dibulan januari sebanyak 2 tema yaitu tema rekreasi selama 3 minggu dan tema pekerjaan selama 2 minggu terjadi interaksi selama 5 kali pertemuan, pertemuan pertama hari rabu pada tanggal 2 januari 2018 pembelajaran dengan tema Rekreasi. Adapun idang pengembangan yang dikembangkan pada pembelajaran yaitu:

1. Nilai moral dan agama: doa naik kendaraan

2. Sosial emosional: belajar antri

3. Bahasa: menyanyi hayu urang jalan -jalan

4. Kognitif: menghitung banyaknya roda keretek/delman

5. Fisik/motorik : kaulinan kukudaan

6. Seni: mewarnai gambar keretek/delman

Pada pertemuan pertama guru dan anak terlihat antusias dengan kegiatan pembelajaran yang sangat menarik menggunakan bahasa sunda yang sederhana dan mudah dipahami. Pertemuan ke dua kegiatan rebo nyunda dilaksanakan pada tanggal 9 januari 2019 masih dengan tema yang sama yaitu rekreasi pada pembelajaran kali ini anak diajak pada kegiatan pengenalan alat tranfortasi yang lain yang digunakan ketika berekreasi, dengan kegiatan sebagai berikut :

1. Nilai moral agama: doa naik kendaraan

2. Sosial emosional: sabar manunggu giliran

3. Bahasa: menyayikan lagu kareta mesin

4. Kognitif: menyusun puzle gambar sepeda atau kareta mesin

5. Fisik motorik: lomba naik sepeda hias (bagi yang memiliki sepeda)

6. Seni: kolase gambar kareta mesin dengan kararas atau daun pisang kering

Pertemuan ke tiga tanggal 16 januari 2019 kegitan rebo nyunda pada minggu 


\section{JURNAL GERIA}

ISSN : 2614-6347 (Print) 2714-4107 (Online)

Vol.2 | No.3 | September 2019

ketiga ini masih dengan tema rekreasi , anak -anak diajak untuk mengenal alat transfortasi yang lain yang biasa digunakan ketika bepergian dalam bahasa sunda tentunya , kegiatan pembelajaran yang disajikan adalah :

1. Nilai moral agama: doa keluar rumah

2. Sosial emosional: mandiri anak diajak untuk mengerjakan pekerjaan sendiri

3. Bahasa: mengenal pupuh balakbak "Rarakitan"

4. Kognitif: menghitung banyak nya batang bambu yang akan dijadikan rakit dalam gambar yang tersedia

5. Fisik motorik: membuat rakit mini dari batang pisang dan dimainkan dikolam kecil

6. Seni :menghias rakit dengan kertas ermas

Kegiatan pada minggu ketiga terlihat semua anak menikmati permainan membuat rakit bahkan menghiasnya tentusaja tanpa meninggalkan kegiatan rebo nyunda yaitu berusaha menggunakan bahasa sunda dalam setiap kesempatan.

Pertemuan ke 4 hari rabu tanggal 23 januari 2019 sudah beralih tema menjadi tema pekerjaan dimana anak -anak dikenalkan macam -macam pekerjaan dalam bahasa sunda misalnya palika adalah nelayan, kamasan pembuat perhiasan , dansebagainya , adapu $\mathrm{n}$ kegiatan pembelajaran nya adalah sebagai berikut :

1. Nilai moral agama: doa sebelum dan sesudah melakukan pekerjaan

2. Sosial emosional: menghargai bahwa setiap pekerjaan adalah mulia/ empati

3. Bahasa: bercakap- cakap tentang patani.

4. Kognitif: Mengelompokkan alat alat yang dibawa patani ketika bekerja Pacul, topi patani, wuluku
5. Fisik motorik: bermain wuluku

6. Seni: menghias topi patani

Pertemuan ke lima hari rabu tanggal 30 Januari 2019 anak diajak untuk mengenal jenis atau macam - macam pekerjaan dalam bahasa sunda lainnya misalnya tukang besi sering disebut pandai besi apasaja yang dibuat tukang besi ketika melakukan pekerjaan ya dengan metode tanya jawab atau bercakap- cakap , kegiatan pembelajaran yang akan dilibatkan pada hari terakahir adalah dengan pembalajaran yang menarik yaitu mengunjungi tukang gerabah atau keramik yang berada disekitar, dengan kegiatan sebagai berikut :

1. Nilai moral agama: doa sebelum dan sesudah melakukan pekerjaan

2. Sosial emosional: empati

3. Bahasa: menyanyi mengenal pupuh balakbak "kusir "

4. Kognitif: bermain peran Menjadi kusir delman

5. Fisik motorik : mengunjungi sentra keramik dengan mengunakan delman

6. Seni : menghias kendi kecil dengan cat air

Pada pertemuan kelima sengaja anak diajak berekreasi dengan menggunakan delman dan bernanyi lagu naek delman hal ini dimaksudkan agar anak lebih dapat mengenal bahasa sunda sekalipun lewat nyanyian, pada kesempatan ini pula para guru diajak mengenal beberapa pupuh yang tentu saja akan mena pmbah wawasan keilmuan para guru dalam memperdalam bahasa sunda terutama pada kegiatan rebo nyunda.

\section{PEMBAHASAN}

Untuk melaksanakan program muatan lokal rebo nyunda , Kabupaten Bandung memiliki motto Sabilulungan yang mamiliki arti yang sangat luas sebagai motivasi bagi semua pihak untuk bekerja 
sama melaksanakan pembangunan disegala bidang. Dalam istilah sunda lebih jauh dijelaskan dengan ungkapan Sabilulungan , sareundeuk saigel, sabobot sapihanean, sabata sarimbagan , rempug jukung sauyunan, rampak gawe babarengan.

Muatan kurikulum lokal kabupaten Bandung memiliki peran ganda sebagai kurikulum pendamping mata pelajaran lainnya sebagi upaya pembentukan karakter yang terintegrasi dengan semua bidang pengembangan yang dapat membentuk karakter setiap anak sesuai potensinya masin- masing.

Contoh salah satu lingkup pembelajarannya adalah sebagai berikut

\begin{tabular}{|c|c|c|}
\hline No & Kel & Ruang Lingkup materi \\
\hline 1 & A & $\begin{array}{l}\text { 1. Menyebutkan nama } \\
\text { sendiri dan anggota } \\
\text { tubuh } \\
\text { 2. Menyebutkan } \\
\text { silsilah keluarga } \\
\text { 3. Menyebutkan benda } \\
\text { yang ada disekitar } \\
\text { rumah dan sekolah } \\
\text { 4. Menyebutkan Nama } \\
\text { teman disekitar } \\
\text { rumahnya } \\
\text { 5. Menyanyikan lagu- } \\
\text { lagu sunda } \\
\text { 6. Mengenal kaulinan } \\
\text { sunda }\end{array}$ \\
\hline 2 & $\mathrm{~B}$ & $\begin{array}{l}\text { 1. } \begin{array}{l}\text { Menyebut nama } \\
\text { sendiri dan anggota } \\
\text { tubuh }\end{array} \\
\text { 2. Menyebutkan } \\
\text { silsilah keluarga } \\
\text { 3. Menyebutkan benda } \\
\text {-benda yang ada } \\
\text { disekitar rumah dan } \\
\text { sekolah } \\
\text { 4. Menyebutkan nama } \\
\text { - nam teman } \\
\text { disekolah dan } \\
\text { rumah }\end{array}$ \\
\hline
\end{tabular}

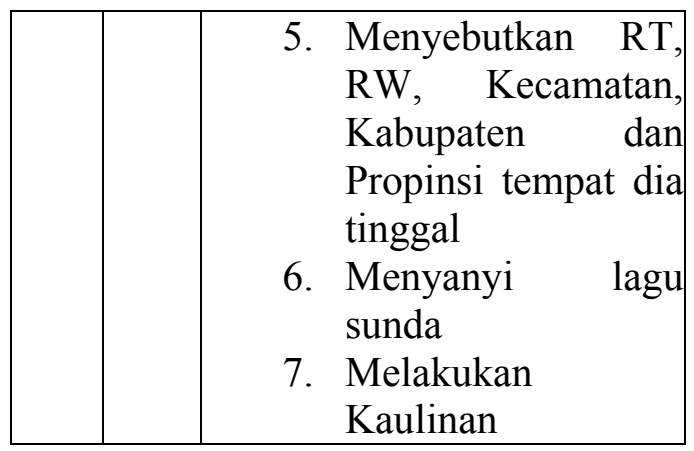

Salah satu contoh Kurikulum kegiatan pembelajaran mulok rebo nyunda ada;lah sebagai berikut:

1. Tema diri sendiri ( 3 minggu )

\begin{tabular}{|c|c|c|c|c|}
\hline $\begin{array}{l}\text { NA } \\
\text { M }\end{array}$ & $\begin{array}{l}\text { SOS } \\
\text { EM }\end{array}$ & BHS & KOG & MOT \\
\hline Doa & $\begin{array}{l}\text { Belaj } \\
\text { ar } \\
\text { antri }\end{array}$ & $\begin{array}{l}\text { Menyeb } \\
\text { utkan } \\
\text { nama } \\
\text { anggota } \\
\text { tubuh : } \\
\text { mastaka } \\
\text {, taraju , } \\
\text { nataan } \\
\text { ramo }\end{array}$ & $\begin{array}{l}\text { Menyu } \\
\text { sun } \\
\text { puzzle } \\
\text { anggot } \\
\text { a tubuh }\end{array}$ & $\begin{array}{l}\text { Menun } \\
\text { juk } \\
\text { dgn } \\
\text { berlari } \\
\text { bagian } \\
\text { tubuh } \\
\text { pada } \\
\text { gamba } \\
\text { r }\end{array}$ \\
\hline
\end{tabular}

Ket :

NAM :Aspek perkembangan Nilai agama dan Moral

SOSEM : Aspek Perkembangan Sosial Emosional

BHS : Aspek perkembangan Bahasa

KOG : Aspek perkembangan Kognitif

MOT: Aspek Perkembangan Motorik kasar maupun Halus

Ada banyak contoh kegiatan yang bisa dipakai ketika kegiatan pembelajaran muatan lokal dilaksanakan, tetapi yang peneliti coba ungkap hanya salah satu saja yaitu tema pertama pada semester pertama. ( Tim pengembang sejarah lokal Kab Bandung Pendidikan Anak Usia Dini , 2014 )

Bentuk kegiatan dalam meningkatkan kemampuan berbahasa sunda pada anak usia dini melalui kegitan rebo nyunda yang diharapkan memiliki pencapaian keberhasilan sebagai berikut : 


\section{JURNAL GERIA}

ISSN : 2614-6347 (Print) 2714-4107 (Online)

Vol.2 | No.3 | September 2019

1. Anak usia dini mampu melafalkan lagu-lagu kaulinan barudak melalui metode bernyanyi melalui kegiatan rebo nyunda

2. Anak usia dini mampu mengikuti kegiatan Rebo nyunda dengan gembira

3. Pendidik dan anak usia dini dapat mengikuti proses belajar mengajar melalui kegiatan rebo nyunda dengan metode bernyayi, bercerita dan kaulinan barudak dengan menyenangkan

\section{KESIMPULAN}

Berdasarkan hasil penelitian yang sudah dilakukan peneliti dalam beberapa pertemuan maka peneliti dapat menyimpulkan bahwa (1) melalui kegiatan muatan lokal rebo nyunda kabupaten Bandung kemampuan berbahasa sunda anak usia dini dapat ditingkatkan, (2) kegiatan Rebo Nyunda yang dikemas dengan menarik dapat meningkatkan antusiasme anak- anak dalam mengembangkan kemampuan berbahasa sunda anak usia dini, (3) Kegiatan Rebo Nyunda akan dapat menigkatkan kemampuan berbahasa sunda setiap anak usia dini dan akan berhasil apabila guru yang menjadi teladan dapat juga menggunakan bahasa sunda dengan baik dalam kegiatan sehari-hari serta (4) Untuk itu peran serta orangtua dan keluarga sebagai pendidikan pertama dan utama dapat memberikan contoh menggunakan bahsa sunda secara baik dan benar dalam kehidupan berkeluarga dan lingkungan dimana anak tinggal.

\section{DAFTAR PUSTAKA}

Arikunto, S. (1999) manajemen penelitian . Jakarta : Rineka Cipta

Fauzidin, M. (2017) Upaya Peningkatan Kemampuan Bahasa Anak 4- 5 tahun Melalui Kegiatan
Menceritakan Kembali Isi Cerita Di

Kelompok Bermain Aisyiah Gobah Kecamatan Tambang Jurnal Obsesi Universitas Pahlawan Tuanku Tambusai vol 1 no 1 Tahun 2017

Khoiruddin. (2017) Pengenalan bahasa arab melalui nyanyian pada anak usia prasekolah di PAUD terpadu Ihyanul ulum puncu Kediri Jatim, Jurnal Obsesi universitas pahlawan Tuanku Tambusai vol 1 no 1 Tahun 2017

Ramadhan, W. (2016) Pengaruh perilaku inisiatif Terhadap kesuksesan Akademik Anak Usia Dini Jurnal Tunas siliwangi Vol. 02 No 01 tahun 2016. Sekolah Tinggi Ilmu Pendidikan Siliwangi ISSN 24769789

Setiawan, D. (2012). Pembelajaran bahasa sunda di PAUD. Retrieved from:

http://.scribd.com/doc/59841368/pe mbelajaran

Tim Pengembang Sejarah Lokal Kabupaten Bandung Pendidikan Anak Usia Dini (2013) Pedoman Khusus Sejarah Lokal Kabupaten Bandung. Bandung: Dinas Pendidikan dan Kebudayaan Kabupaten Bandung bidang sejarah dan kepurbakalaan

Tim Pengembang Sejarah Lokal Kabupaten Bandung Pendidikan Anak Usia Dini (2014) Pedoman Khusus Sejarah Lokal Kabupaten Bandung. Bandung: Dinas Pendidikan dan kebudayaan Kabupaten Bandung bidang sejarah dan kepurbakalaaan 